\section{Risky Sexual Behaviors and Associated Factors among Mizan, Bonga and Tepi Prepa- ratory School Students, South- western, Ethiopia, 2016: A Cross Sectional Study}

\author{
Tensay Kahsay ${ }^{1 *}$, Ayalew Jejaw ${ }^{2}$ and Kebadnew Mulatu ${ }^{3}$ \\ 'Department of Nursing, College of Health Sciences, Mekelle University, \\ Mekelle, Ethiopia \\ ${ }^{2}$ Department of Parasitology, School of Biomedical and Laboratory Sci- \\ ences, College of Medicine and Health Sciences, University of Gondar, \\ Gondar, Ethiopia
}

${ }^{3}$ Department of Public Health, College of Health Sciences, Mizan Tepi University, Mizan Teferi, Ethiopia

\begin{abstract}
Background: The spread of HIVIAIDS in the productive age group especially among adolescents is public health concern in Ethiopia. Pre-college students are more venerable to the spread of HIVIAIDS due to different factors. The aim of this study was to assess risky sexual behaviors and associated factors among Mizan, Bonga and Tepi preparatory school students, southwestern, Ethiopia, 2016.

Methods: Institution based cross-sectional study was conducted by employing both quantitative and qualitative data collection method from November 1 to December 30, 2016. Systematic random sampling technique was employed for study participant selection. Quantitative data was collected by self-administer questionnaire whereas an in-depth interview was used for qualitative data. Descriptive, logistic regression analysis was performed during data analysis.

Results: The overall risky sexual behavior was found to be $25.2 \%$ (119 out of 473). Living away from their parent, students who did not attend religious programs, alcohol drinkers, pornography watchers and monthly family income less than 900 birr were found to be pre-

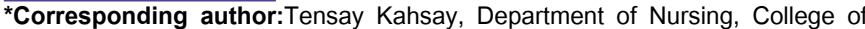
Health Sciences, Mekelle University, Mekelle, Ethiopia, Tel: +251 912937986; E-mail: tensay1221@gmail.com

Citation: Kahsay T, Jejaw A, Mulatu K (2017) Risky Sexual Behaviors and As sociated Factors among Mizan, Bonga and Tepi Preparatory School Students, Southwestern, Ethiopia, 2016: A Cross Sectional Study. J AIDS Clin Res Sex Transm Dis 4: 013.
\end{abstract}

Received: May 01, 2017; Accepted: August 04, 2017; Published: August 18 2017 dictors of risky sexual behavior of the participants.

Conclusion: This study revealed that there is a risky sexual behavior among Mizan, Bonga and Tepi preparatory school students. Therefore responsible bodies should take the initiative to bring about healthy sexual behaviors among school youths.

Keywords: Bonga; Ethiopia; Mizan; Preparatory school; Risk sexual behavior; Tepi

\section{List of abbreviations}

AIDS: Acquired Immune Deficiency Syndrome

AOR: Adjusted Odd Ratio

HIV: Human Immune Deficiency Virus

WHO: World Health Organization

FGD: Focus Group Discussion

STI: Sexually Transmitted Infections

\section{Introduction}

HIV/AIDS has been recognized as one of the major public health as well as development problems in Ethiopia since the mid-1980s. The existence of HIV infection in Ethiopia was recognized in early 1980s with the first two reported AIDS cases in 1986. Since then, the epidemic has hastily spread all through the country. The epidemic peaked in mid-1990s and started to decline in major urban areas since 2000 while stabilizing in rural settings [1]. The national adult HIV prevalence was estimated at $1.5 \%$ (1.9\% for females and $1.0 \%$ for males) in 2011 , ranging from $4.2 \%$ in urban populations to $0.6 \%$ in rural populations [2]. There were an estimated 28,073 deaths due to AIDS in 2010 [3]. According to the World Health Organization (WHO) "adolescents" cover the age of 10 to 19 years; "youths" are defined as belonging to the age group of 15 to 24 years, while the terminology young people covers the age of 10 to 24 years [4].

One-fifth of the world's population includes adolescent and young adults, with more than four-fifths in developing countries. During the transition from childhood to adulthood, youth establish patterns of behavior and make lifestyle choices that affect both their current and future health [5]. Today's adolescent and young adults constitute the largest cohort ever to enter the transition to adulthood. Evidence showed that nearly half of the global populations were less than 25 years old and nearly $90 \%$ live in developing countries. In Ethiopia $45 \%$ of the population under age 15 and $71 \%$ under age of 30 years [6]. Adolescence is characterized by emotional, social and physical transformations that can expose young people to emotional and health vulnerabilities. In this period of development, young people begin to engage in risky behaviors, such as alcohol/drug use and unsafe sex [7].

Adolescence is a critical developmental period when many youth begin to define and clarify their sexual values and start to experiment with sexual behaviors. Most of these youth are students and they are also at a high risk for unsafe sexual behaviors and problems like HIV/ AIDS or STI (Sexually Transmitted Infections), unwanted pregnancy, abortion, poor school performance, high school dropout rate, 
psycho-social problems, conduct disorder, divorce and economic problems $[8,9]$. Sexual behavior and reproductive health of youth in developing countries have attracted a considerable attention over the last 15 years. But, a large proportion of the population in these countries is affected by HIV/AIDS and reproductive health problems. The sexual behavior of youth is important not only because of the possible reproductive outcomes but also because of the fact that risky sexual behavior is associated with sexually transmitted infections $[10,11]$.

\section{Method}

\section{Study area}

Mizan, Tepi and Bonga preparatory schools are among the Ethiopian SNNPR/ Southern Nation Nationality People and Region/preparatory schools, which all were established in 1994 e.c. Mizan preparatory school is found Mizan Teferi town, which is the town of Bench Maji zone, is located $561 \mathrm{kms}$ far from Addis Ababa (the capital city of Ethiopia), Tepi preparatory school is found in Tepi town, $611 \mathrm{kms}$ far from Addis Ababa, which is the town of Sheka Zone and Bonga preparatory school is found in Bonga town of Kefa Zone, $425 \mathrm{kms}$ far from Addis Ababa. The total number of preparatory students attending their education in the study period in the three towns was 1129 (male=644, female=485), 700 (male=378, female=322), 627 (male $=358$, female $=269)$ in Mizan, Bonga and Tepi, respectively. The study was conducted for a month from November 15 to December 15 , 2016.

\section{Study design and Sample size determination}

An institutional based cross sectional study was conducted among students of Mizan, Tepi and Bonga preparatory schools. Sample size was determined using single population proportion formula $\mathrm{n}=\mathrm{Z2} \mathrm{p}$ (1-p)/d2, with the following assumptions: prevalence (p) 43.5\% (12). 95\% confidence level, $5 \%$ margin of error, $5 \%$ for anticipated non-response rate and 1.5 design effect. Accordingly, the minimum sample size (n) was found to be 514 . The total sample size was allocated proportionally to each preparatory school. Multistage sampling technique was used for participant selection. First, list of clusters was established by using grade level in the three schools. Based on the number of students, proportional allocation was deployed to ensure representation total population. By preparing separate sampling frame for each grade level, the sample was proportionally distributed. Finally, a systematic random sampling method was used to select the study participants.

\section{Data collection}

The data was collected by self-administered questionnaire and an in-depth interview. Close-ended with some open-ended questions were used to collect information on socio-demographic variables and risky sexual behaviors. The questionnaire was prepared in English version and then translated in to Amharic version for ease of understanding by the respondents. Finally, it was translated back again in English version to make ease of data analysis.

\section{Specifications of variables}

Non-regular partner: Sexual partner out-off marital union.

Living out of parents: Living away from parent rented may be due to distance and others.

Predisposing factor: Any condition related to biology, cultural, economic, demographic or personal that can increase the risk of involving in risky sexual behavior.
Risky sexual behavior: Those who have one of the following: having more than one sexual partner, performing sexual intercourse with non-regular partner without condom and having sex with commercial sex worker.

Substance use: Use of at least any one of the following substances: alcohol, khat, cigarette shisha, hashish or drug that are assumed to motivate and increase risk of involving in risky sexual behavior.

\section{Data analysis}

Each questionnaire was given a unique code by the HIV/AIDS prevention and control office. The principal investigator prepared template and entered data using Epi-info version 3.5.1. Then, the entered data was cleaned for anomalies prior to data analysis. Frequencies were used to check for missed values and outliers during analysis. Any error was corrected after revision of the original data using the code numbers of the questionnaires. Data was cleaned for inconsistencies and missing values and analyzed using SPSS version 21 statistical software. Frequencies and proportions were computed for description of the study population in relation to socio-demographic and other relevant variables (age, marital status, no children). Significance was checked by chi-square test for categorical variables. Statistical association was determined using crude and adjusted odds ratios with $95 \%$ confidence intervals in binary logistic regression. To assess the association between the different predictor variables of the risk of HIV/AIDS with the dependant variable, first bivariate relationships between each independent variable and outcome was investigated using a binary logistic regression model. Those independent variables that was significant with p-value less than 0.05 at the bivariate level was included in a multivariate logistic regression model for each dependent variable to control for potential confounding variables. The analysis was yield standardized partial regression coefficients that estimate the direct effect of predictor variable on the dependent variable controlling for the effects of all other independent variables in the equation. The results were presented in the form of tables, figures and summary statistics.

\section{Results}

\section{Socio-demographic characteristics}

A total of 473 preparatory students, with the response rate of $92 \%$ participated in the study. Age of the participant ranged from 16-30 years with mean and SD of $18.61+1.64$. About 369 (78.2\%) were between the age of 16-19 and 104 (21.8\%) were aged 20 years and above. Majority of the respondents 274 (57.9\%) were males. Regarding marital status 440 (93\%) was single. About $272(57.5 \%)$ were orthodox religion followers and $342(72.3 \%)$ were attending different religious programs. One hundred eight five (39.1\%) were living away from their parents (Table1).

\section{Risky sexual behaviors}

About 188 (39.7\%) of the respondents had ever practiced sexual intercourse. Of those 96 (51\%) had sexual intercourses with more than one sexual partners. Three-fourth of the respondents started sexual intercourse before the age of 18 years and with mean and SD of $16.8+1.27$. Of the 188 students, who practiced sexual intercourse, $83(44.1 \%)$, had used condoms during their first sexual intercourse and of whom only $38(45.8 \%)$ have used condom consistently. Of the 188 respondents, fifteen $(8 \%)$ respondents had practiced sex with FCS and $71(37.8 \%)$ students had ever practiced sexual intercourse with more than one sexual partner (Table 2). The prevalence of risky sexual behaviors was found to be $25.2 \%$ (119 out of 473 ). Of the 119 
Citation: Kahsay T, Jejaw A, Mulatu K (2017) Risky Sexual Behaviors and Associated Factors among Mizan, Bonga and Tepi Preparatory School Students, Southwestern, Ethiopia, 2016: A Cross Sectional Study. J AIDS Clin Res Sex Transm Dis 4: 013.

- Page 3 of 7 •

\begin{tabular}{|c|c|c|}
\hline Variable & Frequency & Percentage \\
\hline \multicolumn{3}{|l|}{ Grade Level } \\
\hline $11^{\text {th }}$ & 252 & 53.3 \\
\hline $12^{\text {th }}$ & 221 & 46.7 \\
\hline \multicolumn{3}{|l|}{ Sex } \\
\hline Male & 274 & 57.9 \\
\hline Female & 199 & 42.1 \\
\hline \multicolumn{3}{|l|}{ Age } \\
\hline $16-19$ & 369 & 78.2 \\
\hline$>=20$ & 104 & 21.8 \\
\hline \multicolumn{3}{|l|}{ Marital Status } \\
\hline Single & 440 & 93 \\
\hline Married & 18 & 3.8 \\
\hline Living together before marriage & 15 & 3.2 \\
\hline \multicolumn{3}{|l|}{ Religion } \\
\hline Orthodox & 272 & 57.5 \\
\hline Muslim & 71 & 15 \\
\hline Protestant & 110 & 23.3 \\
\hline Catholic & 12 & 2.5 \\
\hline Others & 8 & 1.7 \\
\hline \multicolumn{3}{|l|}{ Living Arrangement } \\
\hline Living with parents & 288 & 60.9 \\
\hline Living away from parents & 185 & 39.1 \\
\hline \multicolumn{3}{|l|}{ Attend Religious Program } \\
\hline Yes & 342 & 72.3 \\
\hline No & 131 & 27.7 \\
\hline \multicolumn{3}{|c|}{ Frequency of Attending Religious Program/Week } \\
\hline 1 to 3 days per week & 220 & 64.3 \\
\hline 4 to 7 days per week & 122 & 35.7 \\
\hline \multicolumn{3}{|l|}{ Month Family Income } \\
\hline $400-900$ & 176 & 37.2 \\
\hline $901-1500$ & 148 & 31.3 \\
\hline$>1501$ & 149 & 31.5 \\
\hline
\end{tabular}

Table 1: Socio-demographic characteristics of study participants in Mizan, Tepi and Bonga preparatory schools SNNPR, Ethiopia, $2016(\mathrm{~N}=473)$.

respondents with risky sexual behaviors, $68.1 \%$ (81 out of 119) were males (Figure 1). It revealed that 146 respondents made unprotected sexual intercourse in the last six months. Of the study participants who practiced unprotected sexual intercourse, $61 \%$ (89 out of 146) made sex with non-regular partners (Figure 2). The major reasons for having sex without condom were to get sexual pleasure since they trust one's partner and followed by peer pressure (Figure 3). The FGD participants mentioned that if they love somebody, they trust and believe that no need to use condom as long as they think they have one lovely one.

\section{Substance use practices and other related behavior}

The prevalence of substance use in this study was $14.4 \%$ ( 68 out of 473). Similarly, 68 (14.4\%) of the respondents had ever gone to night clubs and of these, $60(88.2 \%)$ went 1 to 3 days within a month. About $153(32.3 \%)$ respondents had the habit of watching pornography. Regarding alcohol consumption, 133 (28.1\%) respondents ever used alcohol in the last six months. Off those, 6 (4.5\%) always used it. Fifty-

\begin{tabular}{|c|c|c|}
\hline Variable & Frequency & Percent \\
\hline \multicolumn{3}{|c|}{ Had ever had sexual intercourse } \\
\hline Yes & 188 & 39.7 \\
\hline No & 285 & 60.3 \\
\hline \multicolumn{3}{|l|}{ Sex $=188$} \\
\hline Male & 122 & 64.9 \\
\hline Female & 66 & 35.1 \\
\hline \multicolumn{3}{|l|}{ Age at first sex $n=188$} \\
\hline$<18$ years & 141 & 75 \\
\hline$>=18$ years & 47 & 25 \\
\hline \multicolumn{3}{|l|}{ Sexual partner $n=188$} \\
\hline Regular partner /friend & 89 & 47.3 \\
\hline Non regular partner & 99 & 52.7 \\
\hline \multicolumn{3}{|c|}{ Use condom during the 1 st sexual intercourse $n=188$} \\
\hline Yes & 83 & 44.1 \\
\hline No & 105 & 55.9 \\
\hline \multicolumn{3}{|c|}{ Condom use consistently $n=83$} \\
\hline Yes & 38 & 45.8 \\
\hline No & 45 & 54.2 \\
\hline \multicolumn{3}{|c|}{ Having more than one sexual partner in the last six months } \\
\hline Yes & 96 & 51 \\
\hline No & 92 & 49 \\
\hline \multicolumn{3}{|c|}{ Make unprotected sexual intercourse in the last six months } \\
\hline No & 42 & 22.3 \\
\hline Yes & 146 & 77.7 \\
\hline \multicolumn{3}{|l|}{ Ever had sex with Csw } \\
\hline Yes & 15 & 8 \\
\hline No & 173 & 92 \\
\hline \multicolumn{3}{|c|}{ Number of sexual partner since start sex } \\
\hline One & 117 & 62.2 \\
\hline Two and above & 71 & 37.8 \\
\hline
\end{tabular}

Table 2: Frequency distribution of students to risk sexual behaviors in Mizan, Tepi and Bonga preparatory schools SNNPR, Ethiopia, $2016(\mathrm{~N}=473)$.

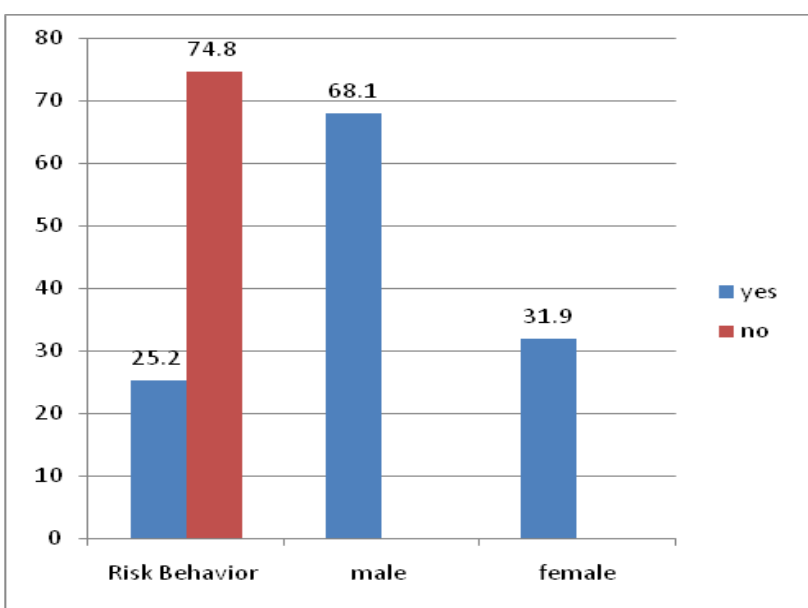

Figure 1: Percentages of risky sexual behaviors based on sex among Mizan, Tepi and Bonga preparatory students, 2016.

N.B: Risky sexual behavior: Practice at least one of the following (Multiple sexual partner, early initiation ofsex, Inconsistent use of condom and Sex with commercial sex workers). 
Citation: Kahsay T, Jejaw A, Mulatu K (2017) Risky Sexual Behaviors and Associated Factors among Mizan, Bonga and Tepi Preparatory School Students, Southwestern, Ethiopia, 2016: A Cross Sectional Study. J AIDS Clin Res Sex Transm Dis 4: 013.

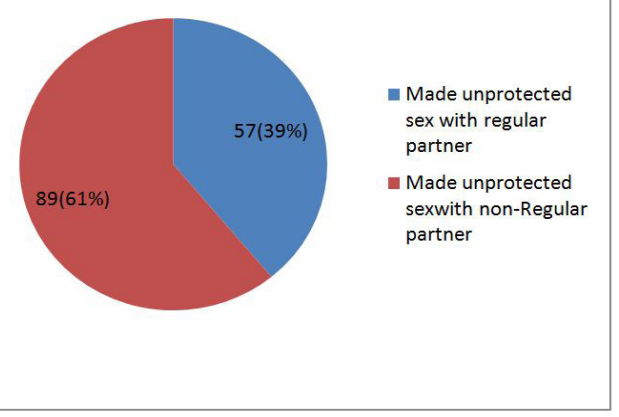

Figure 2: Respondent's frequency distribution regarding unprotected sexual intercourse among Mizan, Tepi, and Bonga preparatory students, 2016.

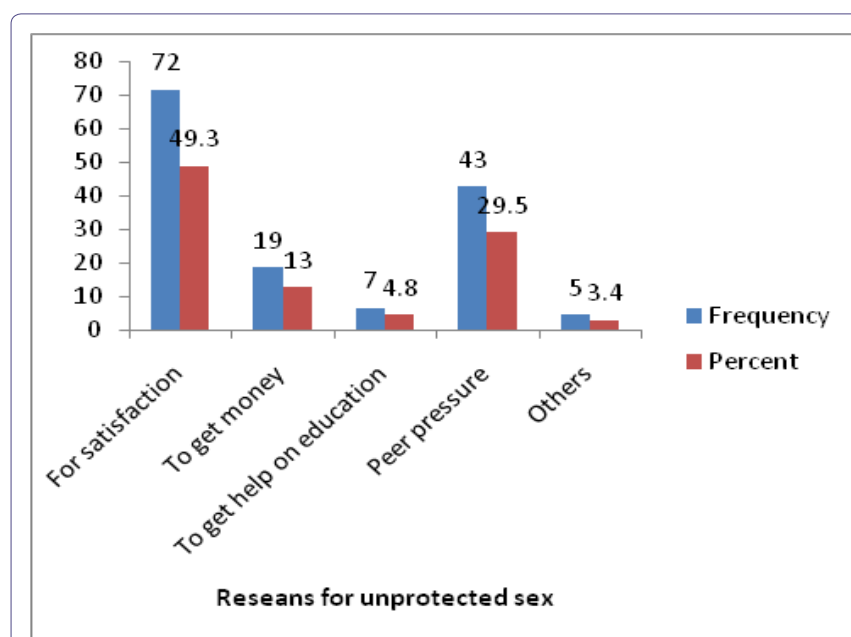

Figure 3: Reasons for unprotected sex among Mizan, Tepi and Bonga preparatory students, 2016.

four (11.4\%) and 17 (3.6\%) respondents ever used khat and shisha, respectively. As far as their sexual behavior in relation to substance use is concerned, $49(72 \%)$ of the respondents made sex after the use of substances and three-fourth (75.6\%) sexual practice were related with alcohol consumption (Table 3 ).

\section{Attitudes towards HIV/AIDS}

Regarding attitude towards HIV/AIDS three questions were asked. Only $13.5 \%$ and $28.3 \%$ of the study participants were strongly agreed and agreed towards the issue of vulnerability of all humans to HIV, respectively. Surprisingly, $38.5 \%$ and $16.5 \%$ of the respondents were disagreed and strongly disagreed about the vulnerability of all humans to HIV, respectively. Moreover, 168 (35.5\%) were strongly agreed as adolescents are highly risky for HIV. Regarding their perception about vulnerability to HIV, 207 (43.8\%) and 17 (35.9\%) of respondents disagreed and strongly disagreed as they are vulnerable to HIV, respectively (Table 4).

\section{Factors associated with risky sexual behaviors}

The result of multiple logistic regression analysis showed that the living arrangement, attend religious programs, consume alcohol the last 6 months, watch pornography and family income of the respondent were found to be significantly associated with risky sexual behavior as

- Page 4 of 7 •

\begin{tabular}{|c|c|c|}
\hline Variable & Frequency & Percent \\
\hline \multicolumn{3}{|l|}{ Ever go to night club } \\
\hline Yes & 68 & 14.4 \\
\hline No & 405 & 85.6 \\
\hline \multicolumn{3}{|l|}{ Frequency Per Month $n=68$} \\
\hline 1 to 3 days/month & 60 & 88.2 \\
\hline 4 and above days /month & 8 & 11.8 \\
\hline \multicolumn{3}{|l|}{ Watch Pornography } \\
\hline Yes & 153 & 32.3 \\
\hline No & 320 & 67.7 \\
\hline \multicolumn{3}{|c|}{ Ever use alcohol in the last six months } \\
\hline Yes & 133 & 28.1 \\
\hline No & 340 & 71.9 \\
\hline \multicolumn{3}{|l|}{ Frequency Per Month } \\
\hline Always & 6 & 4.5 \\
\hline Occasionally & 127 & 95.5 \\
\hline \multicolumn{3}{|l|}{ Use Khat } \\
\hline Yes & 54 & 11.4 \\
\hline No & 419 & 88.6 \\
\hline \multicolumn{3}{|l|}{ Frequency Per Month } \\
\hline Always & 7 & 13 \\
\hline Occasionally & 47 & 87 \\
\hline \multicolumn{3}{|l|}{ Ever use Shisha/Hashish } \\
\hline Yes & 17 & 3.6 \\
\hline No & 457 & 96.4 \\
\hline \multicolumn{3}{|l|}{ Substance Use } \\
\hline Yes & 68 & 14.4 \\
\hline No & 405 & 85.6 \\
\hline \multicolumn{3}{|c|}{ Make sex after use addictive substances $n=68$} \\
\hline Yes & 49 & 72 \\
\hline No & 19 & 18 \\
\hline \multicolumn{3}{|c|}{ After which substance use make sex } \\
\hline Alcohol & 37 & 75.6 \\
\hline Khat & 9 & 18.4 \\
\hline Shisha & 2 & 4 \\
\hline Cigarette & 1 & 2 \\
\hline \multicolumn{3}{|l|}{ Ever got VCT service } \\
\hline Yes & 139 & 29.4 \\
\hline No & 334 & 70.6 \\
\hline
\end{tabular}

Table 3: Frequency distribution of students related to substance use in Mizan Tepi and Bonga preparatory schools SNNPR, Ethiopia, $2016(\mathrm{~N}=473)$.

clearly depicted on table 5 . There is strong association between living arrangement of the student and risky sexual behavior. That is living away from their parent was 3.6 times more vulnerable to risky sexual practices than living with their parents ( $\mathrm{AOR}=3.6,95 \% \mathrm{CI} 1.84-6.89$ ) and those whose did not attend religious programs were 4.1 times more vulnerable to risky sexual behavior than those who attended the programs (AOR=4.1 95\% CI. 2.03-8.11). Alcohol drinking was also significantly associated with risky sexual behaviors. That is, those who drink alcohol were 6.9 times risk to practice risky sexual behavior when compared to those who did not drink alcohol in the last 6 months (AOR=6.9, 95\% CI. 3.35-14.35). 


\begin{tabular}{|c|c|c|}
\hline Variable & Frequency & Percent \\
\hline \multicolumn{3}{|c|}{ All human beings are vulnerable to HIV } \\
\hline Strongly agree & 64 & 13.5 \\
\hline Agree & 134 & 28.3 \\
\hline Disagree & 182 & 38.5 \\
\hline Strongly disagree & 77 & 16.5 \\
\hline I do not know & 16 & 3.4 \\
\hline \multicolumn{3}{|c|}{ Adolescents are highly risk for HIV } \\
\hline Strongly agree & 168 & 35.5 \\
\hline Agree & 170 & 35.9 \\
\hline Disagree & 88 & 18.6 \\
\hline Strongly disagree & 37 & 7.8 \\
\hline I do not know & 10 & 2.1 \\
\hline \multicolumn{3}{|l|}{ You are vulnerable to HIV } \\
\hline Strongly agree & 22 & 4.7 \\
\hline Agree & 64 & 13.5 \\
\hline Disagree & 207 & 43.8 \\
\hline Strongly disagree & 170 & 35.9 \\
\hline I do not know & 10 & 2.1 \\
\hline
\end{tabular}

Table 4: Frequency distribution of students attitude towards HIVIAIDS in Mizan, Tepi and Bonga preparatory schools SNNPR, Ethiopia, $2016(\mathrm{~N}=473)$.

\begin{tabular}{|c|c|c|c|c|}
\hline \multirow{2}{*}{ Variable } & \multicolumn{2}{|c|}{ Risk Behavior } & \multirow{2}{*}{ COR, $95 \% \mathrm{Cl}$} & \multirow{2}{*}{ AOR, $95 \% \mathrm{Cl}$} \\
\hline & No & Yes & & \\
\hline \multicolumn{5}{|l|}{ Sex } \\
\hline Male & 193 & 81 & $1.8(1.147,2.76)^{\star}$ & $0.79(0.40,1.56)$ \\
\hline Female & 161 & 38 & 1 & 1 \\
\hline \multicolumn{5}{|l|}{ Age } \\
\hline $16-19$ & 284 & 85 & 1 & 1 \\
\hline$>20$ & 69 & 34 & $1.7(1.02,2.65)^{*}$ & $1.14(0.56,2.28)$ \\
\hline \multicolumn{5}{|c|}{ Living Arrangement } \\
\hline With family & 253 & 35 & 1 & 1 \\
\hline $\begin{array}{l}\text { Away from } \\
\text { family }\end{array}$ & 101 & 84 & $6.0(3.81,9.49)^{\star}$ & $3.6(1.84,6.89)^{*}$ \\
\hline \multicolumn{5}{|c|}{ Attend Religious Programs } \\
\hline Yes & 295 & 47 & 1 & 1 \\
\hline No & 59 & 72 & $7.7(4.83,12.16)^{\star}$ & $4.1(2.03,8.11)^{\star}$ \\
\hline \multicolumn{5}{|c|}{ Drinking alcohol in the last 6 months } \\
\hline No & 307 & 33 & 1 & 1 \\
\hline Yes & 47 & 86 & $17(10.27,28.21)$ & $6.9(3.35,14.35)^{\star}$ \\
\hline \multicolumn{5}{|c|}{ Show pornography in the last 6 month } \\
\hline No & 297 & 23 & 1 & 1 \\
\hline Yes & 57 & 96 & $21.8\left(12.72,37.17^{*}\right.$ & $7.2(3.67,14.17)^{\star}$ \\
\hline \multicolumn{5}{|l|}{ Chaw Khat } \\
\hline No & 38 & 81 & 1 & 1 \\
\hline Yes & 16 & 38 & $9.9(5.27,18.65)^{\star}$ & $1.5(0.60,3.79)$ \\
\hline \multicolumn{5}{|l|}{ Family Income } \\
\hline 400-900 birr & 114 & 62 & $2.16(1.30,3.58)^{*}$ & $2.6(1.24,5.59)^{\star}$ \\
\hline $901-1500$ birr & 121 & 27 & $0.89(0.49,1.58)$ & $0.86(0.38,1.99)$ \\
\hline$>1500$ birr & 119 & 30 & 1 & \\
\hline
\end{tabular}

Table 5: Bivariate and multivariate logistic regression analysis of factors associated with risk sexual behaviors among preparatory students of Mizan, Tepi, Bonga $(n=473), 2016$.

\section{Discussion}

About 188 (39.7\%) of the respondents had ever practiced sexual intercourse and the majority (64.9\%) who had ever practiced it were males. Three-fourth of the respondents started sexual intercourse before the age of 18 years and with mean and SD of $16.8+1.27$. This finding is in line with study done in Jimma that showed $38.9 \%$ of the respondents had ever had sexual intercourse [12]. On the other hand, this figure is higher than the study finding of Boditi, Humera and Benishangul in which $29.1 \%, 21.8 \%$ and $24.1 \%$ were ever had sexual intercourse, respectively [13-15]. But this finding is low compared to study done from Brazil which showed that $79 \%$ of the students had ever practiced sexual intercourse [16]. This different might be due to socio-cultural variation of the study areas.

This finding indicated that the overall risky sexual behaviors were found to be $25.2 \%$. This result is higher compared to study done in Boditi, Humera and Benishangul which showed that the prevalence of risky behaviors were $17.9 \%, 13.7 \%$ and $19.8 \%$ respectively [13-15]. This disparity might be due to the difference on study period. The attention that was given towards HIV prevention and controlling activities is seemed to be decreased in Ethiopia due to unexplained reasons.

This study also presented that being males behaved more risky sexual behavior than female students (68.1\% male Vs $31.9 \%$ female) and this result is similar to study done in Humera, which showed risky sexual behaviors were predominantly practiced among male students (93.1\% male Vs $6.9 \%$ female) [14]. This may indicated that male adolescents/youth practicing risky sexual behavior could be as a result of substance use and its consequences. About 96 (51\%) of the study participants who had ever practiced sex had more than one sexual partner in the last 6 months. This finding is higher than study finding of Boditi and Benishangul in which $8.7 \%$ and $35.1 \%$ was reported having more than one sexual partner in the last 6 months, respectively $[13,15]$.

In this study $15(8 \%)$ of the study participants who had ever practiced sexual intercourse had practiced sex with commercial sex workers and this is comparatively higher than the study finding from Benishangul that revealed 5.5\% [15]. The major reasons reported for practicing unprotected sexual intercourse encounter in those who ever practiced sexual intercourse $72(49.3 \%)$ of them to get satisfaction and 43 (29.5\%) of the respondents was due to peer pressure. Similarly, studies conducted in Benshangul and Boditi showed that sexual desire and peer pressure were among the motivators with risky sexual behaviors $[13,15]$.

This study found that personal perception about vulnerability to HIV, 207 (43.8\%) and 17 (35.9\%) of respondents disagreed and strongly disagreed as they are vulnerable to HIV, respectively. This is in line with the study conducted from Benshangul it revealed that only $24.5 \%$ of students perceived that they were at risk to HIV infection, $12.7 \%$ did not know whether they are at risk or not and $62.9 \%$ they are perceived not at risk [15]. Low level of risk perception in this study might suggest school youth do not sense the consequence of risky sexual behavior which needs intensive intervention in developing life skills of youth.

The study revealed that risky sexual behavior was significantly associated with living arrangement of the students. Students who were living away from their parent were 3.6 times more vulnerable to risky sexual behavior than living with their parents $(\mathrm{AOR}=3.6,95 \% \mathrm{CI} 1.84$ 6.89). This is in lines with the study's findings of Boditi, Jimma and 
Humera which revealed that students living away from their parents were more likely to practice risky sexual behavior than students who living with their parents [12-14]. This was supported by the FGD and they described the scenario as follows "female students who lived away from parents rented in the town are commonly make a relationship with 'Suger Dady' work in the town, so they are vulnerable to sex related problem and their consequences."

In this study strong association between not attending religious program and risky sexual behavior were observed. Those who did not attend religious programs were 4.1 times more exposed to risky sexual behavior than those who attended religious programs $(\mathrm{AOR}=4.1$ 95\% CI. 2.03-8.11). This study finding was in line with study done in Humera which elaborated not participating in any religious programs [AOR=6.17, 95\% CI. 2.24-17.16] were the factors that increase the odds of practicing risky sexual behavior and Jimma Zone preparatory schools which showed that those who did not visit religious were 6 times risky compare than their counterparts $[12,14]$.

Drinking alcohol was also significantly associated with risky sexual behaviors. That is, those who drink alcohol were 6.9 times risk to practice risky sexual behavior when compared to those who did not drink alcohol in the last 6 months (AOR=6.9, 95\% CI. 3.35-14.35). This study was in agreement with study findings of Jimma, Benishangul and Brazil, which strengthens the association between drinking alcohol and risky behavior $[12,15,16]$. This is supported by the qualitative findings, that is one of the participants described the scenario as follows "students who are addicted by different substance including alcohol are at high risk for HIV/AIDs, since they will not consciously make unprotected sex or they do not consistently use condom."

Similarly, those who watch pornography were 7.2 times more at risk for risky sexual behavior than those who did not watch pornography (AOR=7.2, 95\% CI. 3.67-14.17). This study was consistent with study done in Humera [14] which explained that not exposed to pornographic movie is a factor that prevent $[\mathrm{AOR}=0.36,95 \% \mathrm{CI}: 0.32$ 0.91] the odds of practicing risky sexual behavior among the students. This is supported by the qualitative findings, that is one of the participants described the scenario as follows "nowadays majority youth are involved to sexual experimentation being pushed by impulse due to watch sex imitative films or pornography."

Moreover, monthly family income less than 900 birr were 2.6 times more vulnerable to practice risky sexual behavior than those their family income is greater than 1500 birr ( $\mathrm{AOR}=2.695 \%$ CI. 1.24-5.59). This study is consistent with study done in Hawassa, which reveals that girls who were with low economical status, more likely to had sexual relation with sugar daddies than their counterparts [17]. This is supported by the qualitative findings, that is one of the participants described "student who live away from their parents or live rented from less economic status are mainly influenced to make sexual intercourse with sugar daddies /merchants live in the town for the purpose of money"

The study used both qualitative and quantities data as strong side. On the other hand, the study design was cross-sectional, which implies that the direction of causal relationships cannot always be determined. Moreover, since the issue of sex and related issue are sensitive, the study participants might be biased.

\section{Conclusion}

Considerable proportions of the students were practicing risky sexual behaviors. Not living with family, exposed to pornographic movies, not attending religious programs, drinking alcohol and low family income were the factors that increase the likelihood of practicing risky sexual behavior in the study participants.

\section{Recommendation}

Based on the above findings this study recommends that the Mizan Tepi University HIV/AIDs mainstreaming, school administration and health office of the three zones should take the initiative to bring about healthy sexual behaviors among their school youths by establishing and strengthening anti-AIDS and reproductive health clubs in the schools.

\section{Declarations}

\section{Ethics approval and consent to participate}

The study was conducted after ethical approval was obtained from institutional ethical review committee of Mizan Tepi University. All the study participants and school directors were informed about the purpose of the study. Following an explanation of the purpose, the benefits and the possible risks of the study, written consent was obtained from each studied individuals for participation. The interviews with study participants were conducted with strict privacy and assuring confidentiality.

\section{Funding}

The research was funded by Mizan Tepi University.

\section{Authors' Contributions}

TK involved in the study design, data collection and analysis. AJ involved in the study design, data collection and analysis and drafted the manuscript. KM involved in study design, data collection and analysis. All authors read and approved the final manuscript.

\section{Acknowledgement}

We thank to Mizan Tepi University for the financial support of the study. We also acknowledge the priceless support given by all who participated in the study, especially the study participants and data collectors.

\section{References}

1. OSSREA (2006) The HIVIAIDS Challenge in Africa: An Impact and Response Assessment: Executive Summaries of Findings of Research Projects Carried Out in Ethiopia, Kenya, South Africa, and Zimbabwe. OSSREA, Addis Ababa, Ethiopia Pg no: 101.

2. Tadesse M, Daniel A (2010) Gender Mainstreaming Experiences from Eastern and Southern Africa. African Books Collective, Oxford, England, UK, Pg no: 173.

3. Ahmed FA, Moussa KM, Petterson KO, Asamoah BO (2012) Assessing knowledge, attitude, and practice of emergency contraception: a cross- sectional study among Ethiopian undergraduate female students. BMC Public Health 12: 110 .

4. International Planned Parenthood Federation (IPPF) (1994) Understanding Adolescents, in An IPPF Report on Young People's Sexual and Reproductive Health Needs. London, UK.

5. EPHA (2003) Task force Adolescent Reproductive Health Global and National initiatives: Lesson Learned. EPHA, Belgium.

6. Central Statistical Agency (2014) Ethiopia Mini Demographic and Health Survey 2014. Addis Ababa, Ethiopia. 
Citation: Kahsay T, Jejaw A, Mulatu K (2017) Risky Sexual Behaviors and Associated Factors among Mizan, Bonga and Tepi Preparatory School Students, Southwestern, Ethiopia, 2016: A Cross Sectional Study. J AIDS Clin Res Sex Transm Dis 4: 013.

7. Pharo H, Sim C, Graham M, Gross J, Hayne H (2011) Risky business: executive function, personality, and reckless behavior during adolescence and emerging adulthood. Behav Neurosci 125: 970-978.

8. Prinstein MJ, La Greca AM (2004) Childhood peer rejection and aggression as predictors of adolescent girls' externalizing and health risk behaviors: a 6-year longitudinal study. J Consult Clin Psychol 72: 103-112.

9. Russell TV, Do AN, Setik E, Sullivan PS, Rayle VD, et al. (2007) Sexual risk behaviors for HIVIAIDS in Chuuk State, Micronesia: the case for HIV prevention in vulnerable remote populations. PLoS One 2: 1283.

10. James-Traore T, Magnani R, Murray N, Senderowitz J, Speizer I, et al. (2002) Intervention strategies that work for youth: Summary of focus on young adults End of program report. North Carolina, USA.

11. Scholl Ed, Schueller J, Gashaw M, Wagaw A, Michael LW (2004) Assessment of Youth Reproductive Health Programs in Ethiopia. USAID, Washington, D.C, USA.

12. Fentahun N, Mamo A (2014) Risky sexual behaviors and associated factors among male and female students in Jimma zone preparatory schools, south west Ethiopia: comparative study. Ethiop J Health Sci 24: 59-68.
13. Daka D, Shaweno D (2014) Magnitude of risky sexual behavior among high school adolescents in Ethiopia: A cross-sectional study. J Public health Epidemiol 6: 211-215.

14. Dadi AF, Teklu FG (2014) Risky sexual behavior and associated factors among grade 9-12 students in Humera secondary school, western zone of Tigray, NW Ethiopia, 2014. J Public Health 2: 410-416.

15. Agajie M, Belachew T, Tilahun T, Amentie M (2015) Risky Sexual Behavior and Associated Factors Among High School Youth in Pawe Woreda Benishangul Gumuz Region. J Clin Med 4: 67-75.

16. Sanchez ZM, Martins SS, Opaleye ES, Moura YG, Locatelli DP, et al. (2011) Social factors associated to binge drinking: a cross-sectional survey among Brazilian students in private high schools. BMC Public Health 11: 201.

17. Molla M, Mitiku L (2001) Transactional Sex with "Sugar Daddies" among Female Preparatory Students: HIV Risk Assessment in Hawassa Town, SNNPR, Ethiopia. Collage of Health Science, School of Public Health, Addis Ababa, Ethiopia. 